\title{
A novel application of temporoparietal fasciocutaneus (TPFC) and temporoparietal (TPF) pedicle flap for auricular reconstruction
}

Aleksander Zwierz ( $\nabla$ aleksanderzwierz@gmail.com )

Nicolaus Copernicus University in Torun: Uniwersytet Mikolaja Kopernika w Toruniu https://orcid.org/0000-0002-5824-8709

Krystyna Masna

Nicolaus Copernicus University in Torun: Uniwersytet Mikolaja Kopernika w Toruniu

Paweł Burduk

Nicolaus Copernicus University in Torun: Uniwersytet Mikolaja Kopernika w Toruniu

\section{Case report}

Keywords: Temporoparietal fasciocutaneus (TPFC), temporoparietal (TPF) pedicle flaps, auricular reconstruction

Posted Date: April 1st, 2021

DOl: https://doi.org/10.21203/rs.3.rs-351141/v1

License: (9) (1) This work is licensed under a Creative Commons Attribution 4.0 International License. Read Full License 


\section{Abstract}

Background: Temporoparietal fasciocutaneus (TPFC) and temporoparietal (TPF) pedicle flaps play an important role among many techniques for auricular reconstruction. Because of their unique characteristics, the flaps based on the superficial temporal artery (STA) may be used for various types of reconstruction.

Case series presentation: In this paper, we present several applications of the TPFC and TPF pedicle flaps in the reconstruction of defects after ear resection, including the use of the sandwich flap and preparing basis for Vistafix $\circledR^{\text {system. }}$

Conclusion: Our experiences presented in this case series confirm the reconstructive potential of the flaps, also in patients in whom the Vistafix ${ }^{\circledR}$ system was used for reconstruction of the ear. In all cases described herein, the use of the pedicle flaps resulted in optimal healing and satisfactory cosmetic and functional outcomes.

\section{Introduction}

A consequence of radical oncological resection or scar tissue formation in the facial region may be a deficiency of the skin and supporting tissues, causing difficulties with primary closure. One of the best reconstructive options in such cases is the use of regional flaps. Among the latter, temporoparietal pedicle flap (TPF) seems to be the most feasible option. The advantages of the TPF include its consistent anatomy, in $90 \%$ of the cases based on the superficial temporal artery (STA) and veins, adequate blood supply, proximity to the recipient sites, and presence of a long, thin, pliable and resistant vascular peduncle which provides wide arc of rotation, with the possibility of up to 12-cm translocation of the flap [1]. The TPF cannot be easily distinguished from surrounding skin at the recipient site and because of the excellent blood supply is resistant to infections. Given the anatomical division of the STA, two skin island flaps based on its frontal and parietal branches can be used. Further, Benlier reported on the use of reverse TPF with the utilization of reverse blood flow from an anastomotic network of the supratrochlear and supraorbital arteries to the frontal branch and anastomotic connection between the occipital artery and the parietal branch [2,3]. Due to all the characteristics mentioned above, the TPF has a high survivability rate and can provide an optimal blood supply for other transplanted tissues $[4,5,6]$.

Surgical technique

The STA can be identified using Doppler imaging or through palpation, underneath the skin covering the zygomatic arch, $2 \mathrm{~cm}$ superiorly and anteriorly from the external auditory canal. Following the identification and marking of the vessel, the lines of skin incisions and the borders of the skin flaps are planned (Fig. 3A). The vertical incision is made from the root of the helix towards the superior temporal line. The incision is continued towards the posterior margin of the flap if the latter is planned to be based on the frontal branch of the STA or towards its anterior margin if based on the parietal branch. Usually, the STA is accompanied by one or two veins that run above the artery and should be spared [1]. During 
the incision, an injury to the temporal branch of the facial nerve should be avoided as well. At the level of the zygomatic arch, the temporal branch gives off 2-4 ramifications that run underneath the TPF, 12-14 $\mathrm{mm}$ anteriorly to the articular eminence of the zygoma $[7,8]$. The anterior scalp flap is elevated through the meticulous sharp dissection in the subdermal plane. It is essential to continue the dissection slightly below the hair follicles, to leave a thin layer of subcutaneous fibrofatty tissue, and hence, to prevent local alopecia. The STA is identified $0.5-1 \mathrm{~cm}$ anteriorly from the root of the helix, and then, the dissection is continued peripherally along the vessel. Once the planed skin island has been reached, a circular incision is tailored around it. The island receives blood supply from the STA via perforator vessels. It is crucial to tailor the skin flap around the STA, located in the layer underneath (Fig. 1D). Then, the skin island is raised caudally together with the TPF, released from loose areolar tissue, trimmed to the required size with sparing the vascular pedicles, and tailored inferiorly, down to the parotid gland. Finally, the TPFC flap is rotated to the recipient site. If the TPF is used, it can be covered with a split skin graft, which may be meshed. If the reconstruction extends to the posterior part of the external auditory canal, the transplant is stabilized using a cotton pledge with antibiotic ointment, maintained for up to three weeks.

\section{Case Presentation}

\section{Case 1}

A 64-year-old man with a history of SCC arising from the triangular fossa and crura of the antihelix and invading the upper third of the left ear, underwent a hemiresection of the auricle with subsequent reconstruction using the TPFC "sandwich" flap (Fig. 1). The auricle was reconstructed by bending the flap composed of two skin islands. Additionally, two other foci of basal cell carcinoma were resected from the same side of the head. The skin defect was covered by a split skin graft taken from the femur. Complete reception of the flap was achieved, with good healing and satisfactory cosmetic outcome.

\section{Case 2}

A 65-years-old man was admitted to our clinic with a history of malignant lesions of the left external ear, SCC. Tumor involved middle third of the auriculae with helix erosion (Fig. 2). Triangle subtotal excision of the primary lesion with a $1 \mathrm{~cm}$ margin of macroscopically healthy tissue, was performed above antirtagus to the triangular fossa with leaving helical root and crus. Histologically controlled excision was performed until the margins were pathohistologically free. Partial auricular reconstruction with the defect coverage using the TPFC "sandwich" flap was done. The flap completely healed and cosmetic result was acceptable.

\section{Case 3}

A 66-year-old man was admitted with an invasive metatypical basal cell carcinoma of the right auricular concha (type IV according to Bukal) [9]. The round tumor, $7 \mathrm{~mm}$ in diameter, was resected along with the cartilage of the concha. The defect was reconstructed with the TPFC flap based on the frontal branch of 
the STA (Fig. 3). The operated site healed well, and the patient considered cosmetic outcome acceptable and resigned from the flap thinning.

\section{Case 4}

A 38-year-old man with an eroding oval metatypical BCC $(5 \mathrm{~mm} \times 7 \mathrm{~mm})$ located in the left cavum concha underwent a full-thickness resection of the concha and intratragal notch, with the resection margin involving the antitragus, antihelix, antihelix inferior crura, crus of the helix and posterior cartilaginous part of the external auditory canal. The retroauricular skin was sutured with the remaining postauricular skin raised from the antihelix fossa. The concha was reconstructed with the TPFC flap based on the parietal branch of the STA (Fig. 4). A good cosmetic outcome was obtained, with no evidence of cancer recurrence during subsequent control visits.

\section{Case 5}

An 88-year-old man was admitted due to invasive recurrence of basalioma exulcerans diagnosed six months after Burow's triangle resection of helical BCC in the left auricle. The patient underwent total auricular resection with mastoidectomy and posterior wall resection. The mastoid was obliterated with the use of a temporal muscle flap based on the middle temporal artery (Hong Kong flap). Then, the whole postauricular surface was refined by the TPF and covered with a split-thickness mashed skin graft. The second split-thickness skin flap was inserted into the external auditory canal to reconstruct the posterior wall (Fig. 5). Four weeks later, the surface was smooth enough to perform external ear reconstruction in preparation for the use of the Vistafix ${ }^{\circledR}$ system. No signs of carcinoma recurrence were observed during a 12-month follow-up, and the patient could eventually undergo the secondary reconstruction of the auricle with the prosthesis based on the Vistafix® system.

\section{Case 6}

A 60-year-old man was admitted with unilateral right-side microtia and a history of 20 previous auricular reconstructions. The patient opted for the resection of scar tissue and residual cartilage used for auricular reconstruction, but he was offered reconstruction with the Vistafix® system instead. All scar tissue and the remnants from previous unsuccessful reconstructions were removed. Then, two transcutaneous titanium osteointegrated implants were mounted into the temporal bone, and the whole surface was covered by the TPF and mashed split skin graft (Fig. 6). During the same procedure, a magnetic implant system of the bone conductive hearing device was installed in the temporal bone. The TPF covered the bone and provided a thin protective layer and good vascular support for the mashed split skin graft. Good healing and smooth surface were achieved six weeks after the procedure, and the patient could undergo auricular reconstruction with epithesis connected to the Vistafix® system (Fig. 7).

\section{Discussion}


Surgical reconstruction of the ear still constitutes a challenge. To achieve a satisfactory outcome of auricular reconstruction both in terms of esthetics and function, the surgeon needs to transfer tissues from other areas. Given their proximity, versatile form without a skin island or with up to two islands, and excellent blood supply, the reconstruction with STA-based pedicle flaps seems to be an optimal solution $[1,8,10]$.

In the first case reported herein, the novel use of the TPFC sandwich flap provided a similar rigidity of the upper half of the reconstructed auricle as in the case of the reconstruction with moulded cartilage or polypropylene (MEDPOR) covered by the skin. The cartilaginous framework for the reconstruction of the auricle was first described by Tanzer in 1959. However, the outcomes of this method were not entirely satisfactory due to the frequent occurrence of atrophy or cartilage remodeling $[11,12]$. To overcome this problem, polypropylene (MEDPOR) has been introduced by Reinisch, but according to many authors, this material was not superior to the cartilage $[13,14,15]$. Although our patient has been wearing glasses, we did not need to use an additional framework to strengthen the reconstructed auricle. The rigid structure of the auricle was achieved by bending the flap, which, importantly, neither restricted the blood flow in the vascular pedicle nor impaired the blood supply of the reconstructed ear. Our experiences with another two patients confirmed high effectiveness of flaps based on the frontal and parietal branches of the STA. In all our patients who underwent auricular reconstruction with the TPFC, the redness of the skin flap was apparent a few days after the surgery; according to many authors, this is a sign of an excellent blood supply and fast healing of the tissue $[2,4,5,10,16,17]$. Given the fast and uneventful healing, the patients after auricular reconstruction with regional flaps were relatively early eligible for adjuvant treatment, such as radiotherapy and chemotherapy. A minor disadvantage of the reconstruction with the TPFC is the necessity to shave the hair growing on the newly formed auricle.

Not infrequently, despite multiple attempts and many reconstructive surgeries, the outcomes of auricular reconstruction and autologous repair are poor, and the patient requires implantation of an auricular prosthesis. This procedure needs to be preceded by appropriate preparation of the surface, to increase the likelihood of optimal fixation of titanium implants and good healing. Osteointegration is a gradual process characterized by the periodical appearance of various tissues, such as bloody corpuscles and trabecular bone. For the first seven days, the interface between the implant and the bone is filled by aqueous cellular elements and lacks a mineralized matrix [18]. As a result, the resistivity of the interface is approximately 100,000 times lower than in the case of mature bone [19]. The technique used in our two patients (Cases 5 and 6) stimulated healing, provided better stability for the transcutaneous implants and good adherence of the epithesis.

\section{Conclusion}

Because of their unique characteristics, the flaps based on the STA may be used for various types of auricular reconstruction. Depending on the application, the flaps can be thin and flexible or thick and rigid, standalone or connected to a skin island. Regardless of the form, the flaps retain their primary advantage, i.e. constant and adequate blood supply, and hence, can be used to cover other poorly perfused tissues or 
auricular implants, improving healing thereof and providing better stability. In this case series, we present good results obtained with TPFC pedicle flaps based on the temporal or parietal branch of the STA.

Moreover, we describe a new application of the TPFC flap for auricular reconstruction with epithesis connected to the Vistafix ${ }^{\circledR}$ system and simultaneous, sequential implantation of transcutaneous titanium screws. In these cases, we used the TPF to prepare a smooth scaffold for the split skin graft and to envelop the titanium implants. The TPF, the thinnest flap in the human body, provided excellent blood supply for adjacent tissues, promoted osteointegration of the implants and prevented local infection, at the same time forming a smooth adhesive surface for the auricular prosthesis.

\section{Declarations}

Acknowledgments

Declaration of Conflicting Interests:

The authors declare that there is no conflict of interest.

Ethics:

This article describes the stage of the case at the time of treatment in accordance with current standards. Consent from the Ethics Committee was not required.

\section{References}

1. Park C, Lew DH, Yo WM. An analysis of 123 temporoparietal fascial flaps: Anatomic and clinical considerations in total auricular reconstruction. Plast Reconstr Surg. 1999;104:1295e306.

2. Benlier E, Top H, Cinar C, Yazar S, Aygit AC, Cetinkale O. Reverse-flow retroauricular island flap in facial reconstruction. Dermatol Surg. 2007;33:1442e50.

3. Yamauchi M, Yotsuyanagi T, Ezoe K, Saito T, Ikeda K, Arai K. Reverse facial artery flap from the submental region. J Plast Reconstr Aesthet Surg. 2010 Apr;63(4):583-8. doi:

10.1016/j.bjps.2009.01.035. Epub 2009 Mar 3. PMID: 19261559.

4. Yung M. The Use of Temporoparietal Fascial Flap to Eliminate Wound Breakdown in Subtotal Petrosectomy for Chronic Discharging Ears. Otology Neurotology. 2016;37:1. 10.1097/MA0.0000000000000959.

5. Ubaidullo Kurbonov A, Davlatov S, Janobilova Z, Kurbanov. Massoud Mirshahi The Use of Temporoparietal Fascia Flap for Surgical Treatment of Traumatic Auricle Defects Plast Reconstr Surg Glob Open. 2018 May; 6(5): e1741. Published online 2018 May 2. doi:

10.1097/GOX.0000000000001741 PMCID: PMC5999426.

6. Din Lam, Eric R, Carlson. The temporalis muscle flap and temporoparietal fascial flap Oral Maxillofac Surg Clin North Am. 2014 Aug;26(3):359-69. doi: 10.1016/j.coms.2014.05.004. 
7. Technique of Temporoparietal Fascia Flap in Ear and Lateral Skull Base Surgery Stow. Nicholas W, Gordon DHt, Eisenberg R. Technique of Temporoparietal Fascia Flap in Ear and Lateral Skull Base Surgery. Otology \& Neurotology: August 2010 - Volume 31 - Issue 6 - p 964-967 doi: 10.1097/MAO.0b013e3181e3d33c.

8. Jaquet Y,b; Higgins, Kevin M, Enepekides, Danny J. The temporoparietal fascia flap: a versatile tool in head and neck reconstruction Current Opinion in Otolaryngology \& Head and Neck Surgery: August 2011 - Volume 19 - Issue 4 - p 235-241 doi: 10.1097/M00.0b013e328347f87a.

9. Bukal J, Fries R, Engleder R, Platz H. Zur Klinik der Basaliome, Plattenepithelkarzinome und Keratoakanthome der Gesichts- und Halshaut. In: Pfeifer G, Schwenzer N, Hrsg. Fortschritte der Kieferund Gesichtschirurgie. 1982; XXVII.

10. Collar R, Zopf D, Brown D, Fung K, Kim J. (2011). The versatility of the temporoparietal fascia flap in head and neck reconstruction. Journal of plastic, reconstructive \& aesthetic surgery: JPRAS. 65. 141-8. 10.1016/j.bjps.2011.05.003.

11. Tanzer RC. Total reconstruction of the external ear. Plast Reconstr Surg Transplant Bull. 1959;23:115.

12. Brent B. Auricular repair with autogenous rib cartilage grafts: two decades of experience with 600 cases. Plast Reconstr Surg. 1992;90:355-74. discussion 375-376.

13. Reinisch JF, Lewin S. Ear reconstruction using a porous polyethylene framework and temporoparietal fascia flap. Facial Plast Surg. 2009;25:181-9.

14. Firmin F. State-of-the-art autogenous ear reconstruction in cases of microtia. Adv Otorhinolaryngol. 2010;68:25-52.

15. Park SS, Wang TD. Temporoparietal fascial flap in auricular reconstruction. Facial Plast Surg. 1995 Oct;11(4):330-7. doi: 10.1055/s-2008-1064549. PMID: 9046621.

16. Tellioğlu AT, Tekdemir I, Erdemli EA, Tüccar E, Ulusoy G. Temporoparietal fascia: an anatomic and histologic reinvestigation with new potential clinical applications. Plast Reconstr Surg. 2000 Jan;105(1):40 - 5. doi: 10.1097/00006534-200001000-00007. PMID: 10626968.

17. Raffaini M, Costa P. The temporoparietal fascial flap in reconstruction of the cranio-maxillofacial area. J Craniomaxillofac Surg. 1994 Oct;22(5):261-7. doi: 10.1016/s1010-5182(05)80073-3.PMID: 7798355.

18. Franchi M, Fini M, Martini P, Orsini E, Leonardi L, Ruggeri A, Giavaresi G, Ottani V. Biological fixation of endosseous implants. Micron. 2005b;36:665-71.

19. Clemente F, Costa M, Monini S, Barbara M. (2011). Monitoring of Fixture Osteointegration after BAHA® Implantation. Audiology \& neuro-otology. 16. 158 - 63. 10.1159/000316677.

\section{Figures}




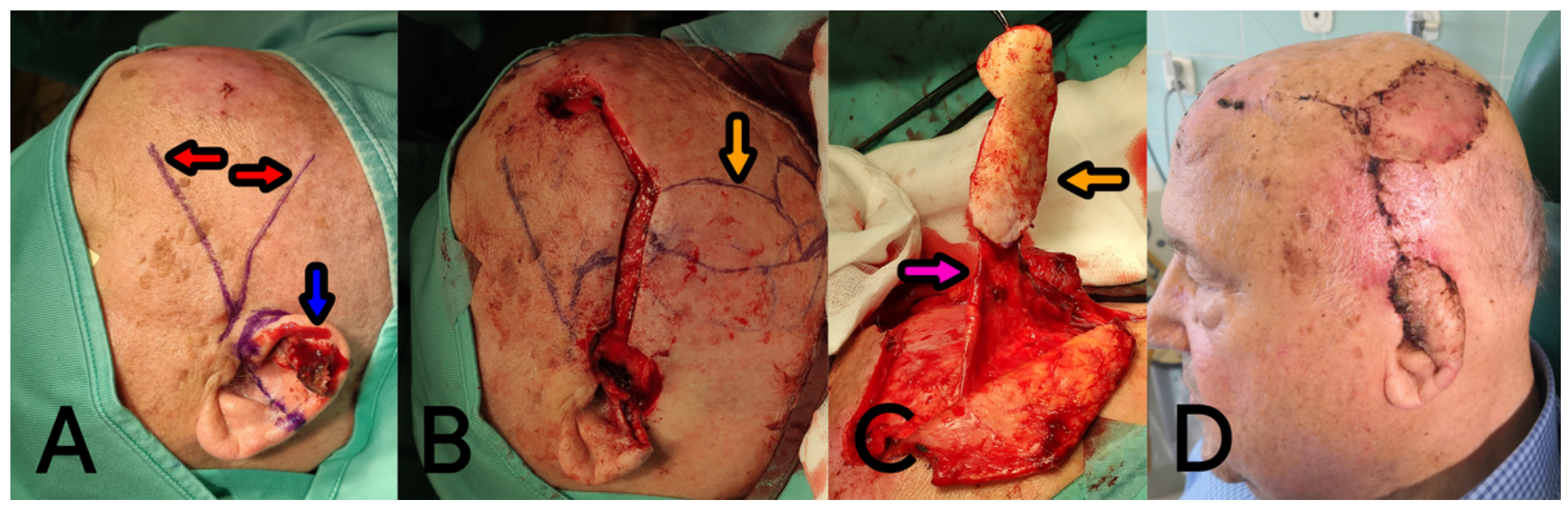

\section{Figure 1}

The use of TPFC "sandwich" flap for upper part of the auricle reconstruction. A. Range of resection and flap planning before surgery. Tumor -blue arrow, Frontal and parietal branches of the superficial temporal artery -red arrow. B. View after tumor resection, preparing the flap -orange arrow. C. Skin island -orange arrow, pedicle - rose arrow. D. Patient two weeks after surgery.

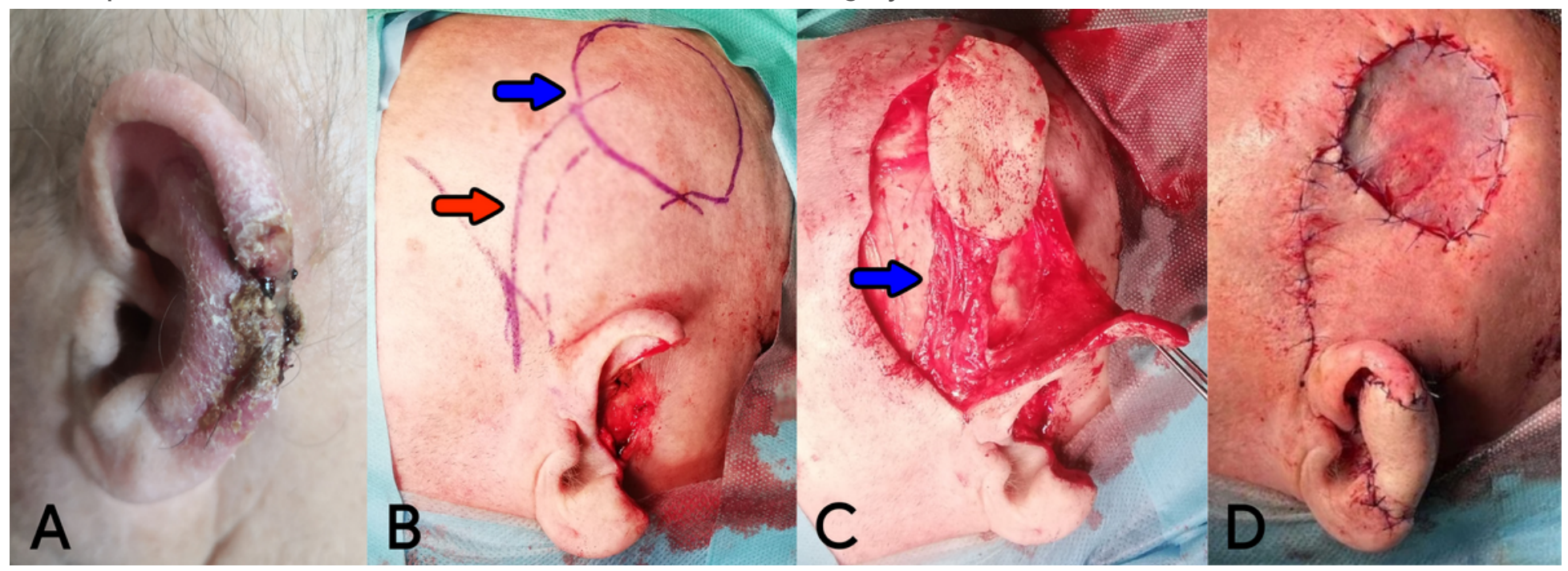

Figure 2

The use of TPFC "sandwich" flap for middle third auricular defect reconstruction. A. Tumor. B Flap planning- blue arrow, STA parietal branch red arrow, C Raised flap, pedicle blue arrow, D. Final result with flap translocation. 


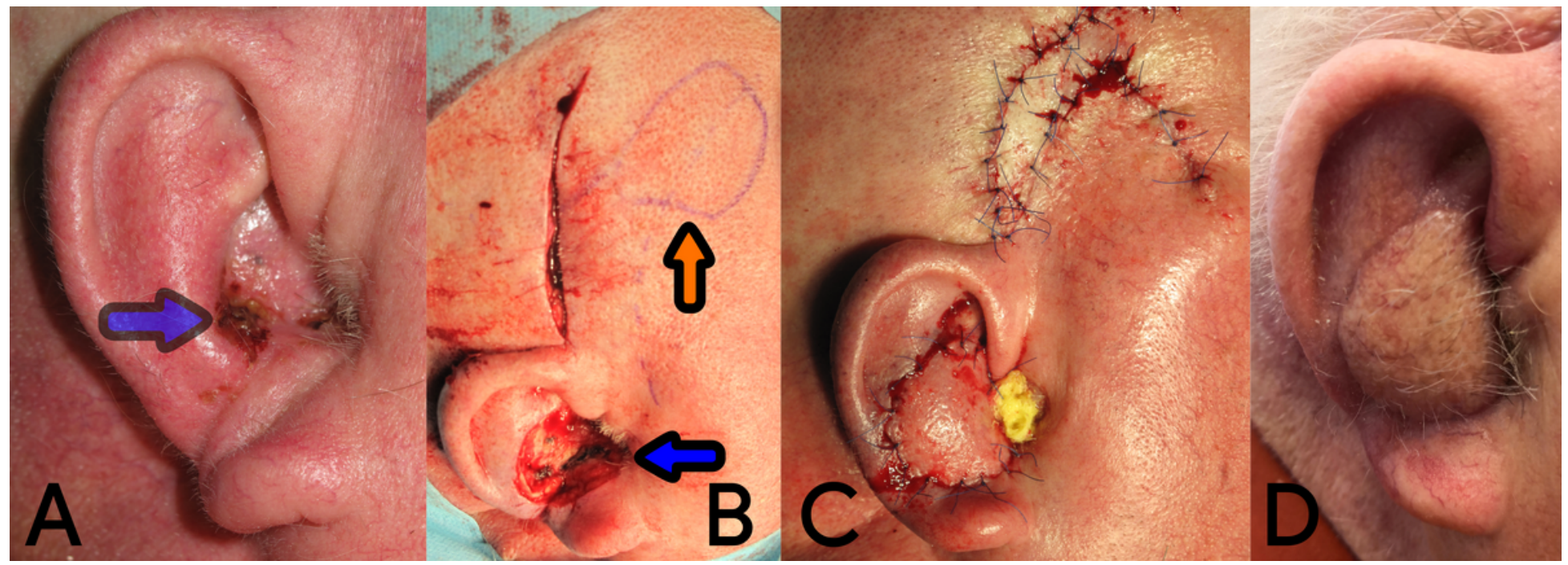

\section{Figure 3}

The use of TPFC for auricular concha reconstruction. A. Before surgery, tumor -blue arrow. B. TPFC Flap planning -orange arrow. C Final result after surgery. D. Patient two weeks after surgery.

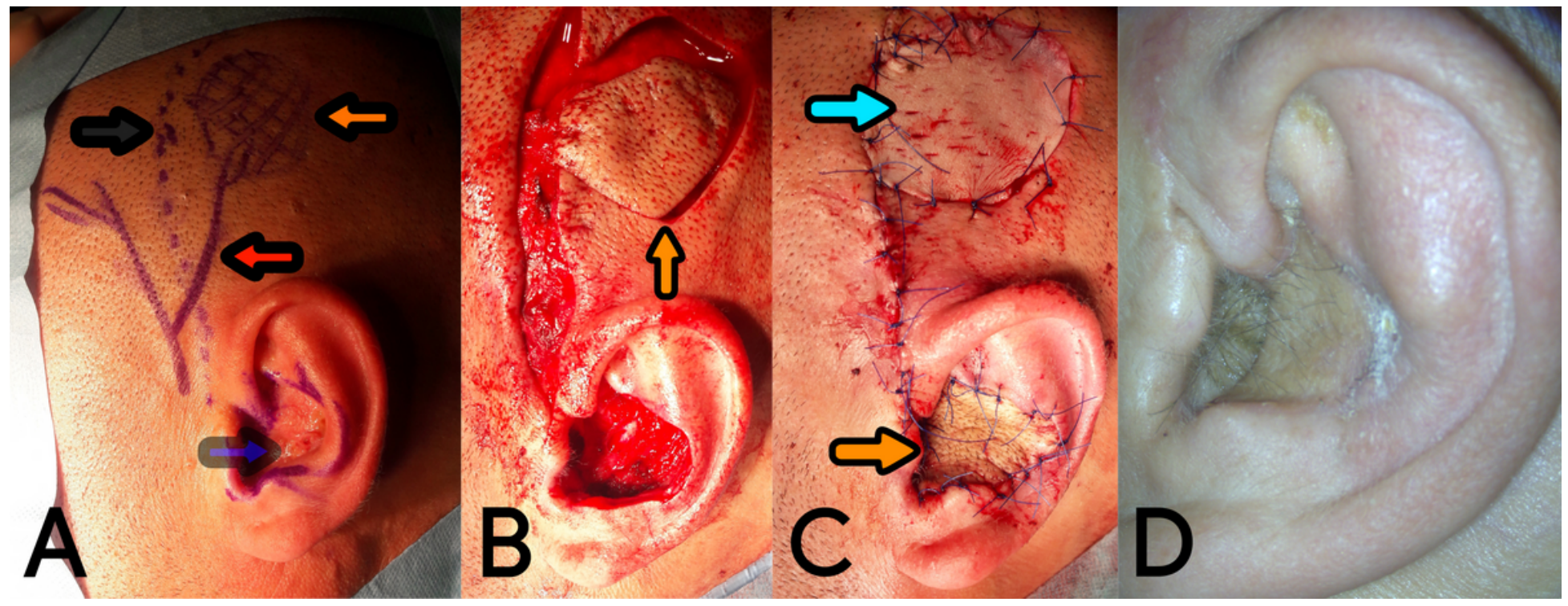

\section{Figure 4}

The use of TPFC for auricular concha reconstruction. A. Patient before surgery, tumor -blue arrow, flap planning- orange arrow, parietal branch of the STA red arrow. B. Skin flap - orange arrow. C. Flap transferred and sutured in place - orange arrow, split thickness skin graft covering donor's place. D. Patient two weeks after surgery. 


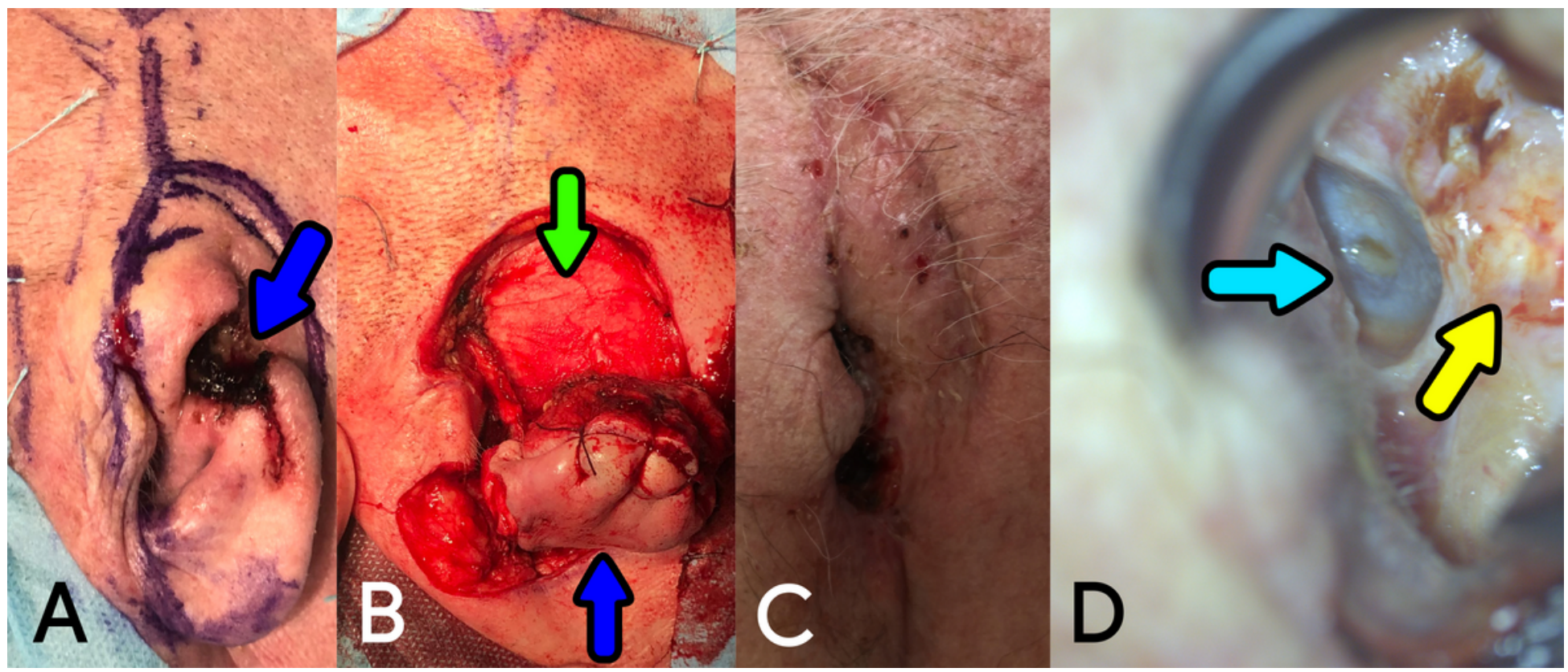

Figure 5

The use TPF flap for closing soft tissue defect after auricular and temporal bone resection. A Range of resection, tumor- blue arrow, B. TPF flap- green arrow, area of resection - blue arrow, C. Patient two weeks after surgery. D. Microscopic view two weeks after surgery-tympanic membrane - light blue arrow, mastoid obliterated by temporalis muscle flap and covered with split thickness skin graft-yellow arrow.

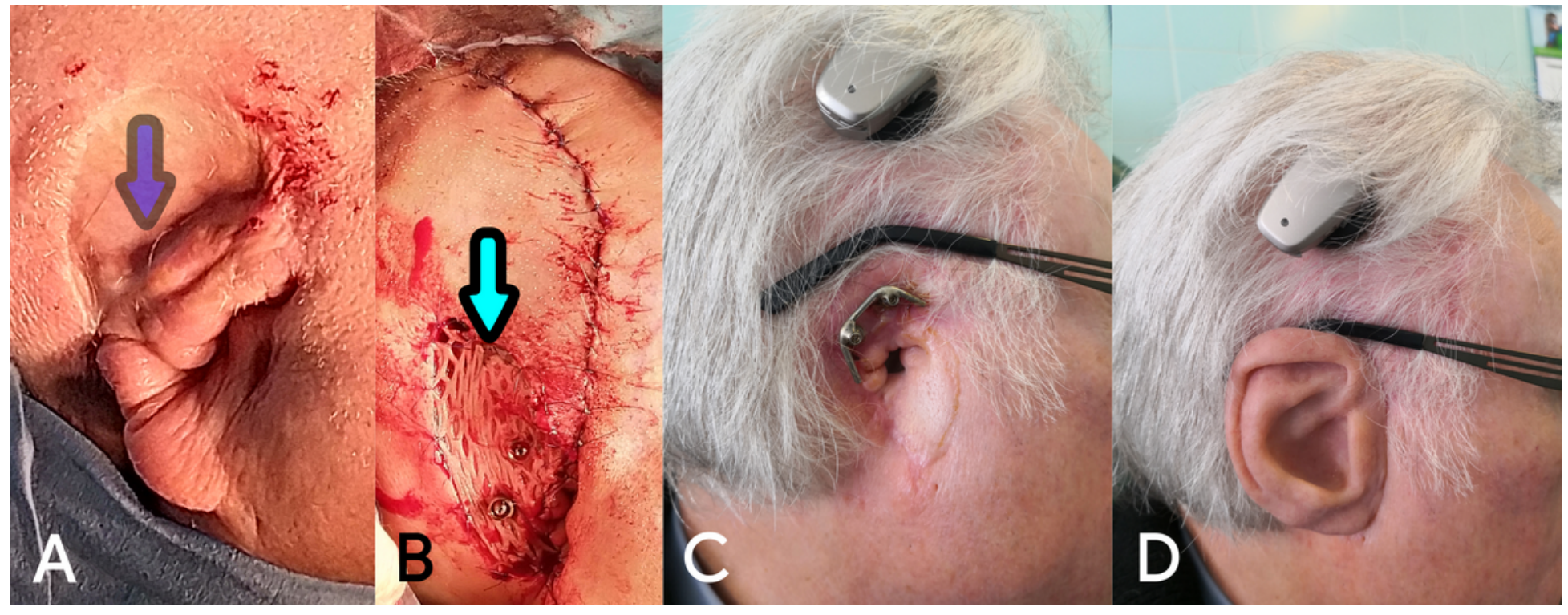

\section{Figure 6}

The use TPF flap for closing soft tissue defect after 20 unsuccessful auricular reconstructions. A. Auricular and scar tissue - blue arrow. B Split thickness meshed skin graft lays on TPF flap - light blue. C Implants and attachment for epithesis. D. Fixed epithesis. 


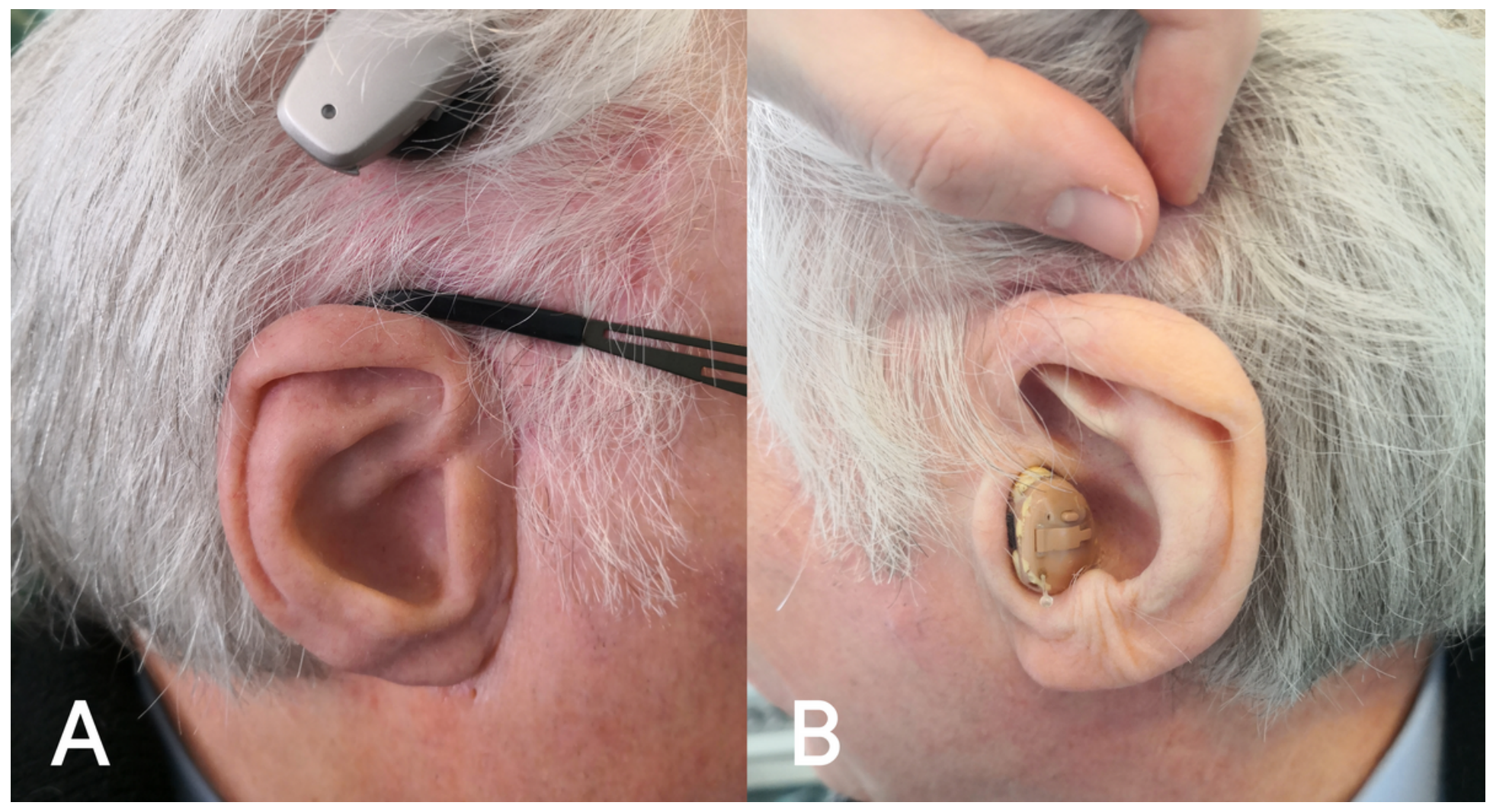

Figure 7

Comparison of the right auricular prothesis $(A)$ with left ear $(B)$. 